\title{
The role of proprioception in the perception and control of human movement: Toward a theoretical reassessment
}

\author{
J. A. SCOTT KELSO and KENNETH G. HOLT \\ Haskins Laboratories, New Haven, Connecticut 06510 \\ and the Departments of Psychology and Biobehavioral Sciences \\ University of Connecticut, Storrs, Connecticut 06268
}

and

\author{
ADRIAN E. FLATT \\ Department of Surgery, Norwalk Hospital, Norwalk, Connecticut 06856
}

\begin{abstract}
The theoretical role of proprioception in the perception and control of human movement is elusive because of the obvious inability to manipulate experimentally the various receptive systems. Individuals who have had the metacarpophalangeal joint and joint capsule removed and replaced with silastic inserts afford a unique opportunity to evaluate a principal source of proprioception, namely, slowly adapting joint afferents. In a set of experiments, we show that such individuals show no deficits in finger localization following joint replacement. We take this and other complementary findings as a preliminary basis for proposing a dynamic rather than kinematic account of movement production. In addition, we provide a reconceptualization of the function of proprioceptive information in the CNS. Our arguments focus on proprioceptive inputs as tuning or modulating interneuronal pools rather than providing dimension-specific information to the brain, as is commonly assumed.
\end{abstract}

An important limitation in seeking to understand the control of human movement is that of being confined by necessity to observations about motor output from which to infer the nature of the underlying processes. It is always difficult to discern which aspects of the motor output represent central control and which components reflect peripheral contributions. A major tack on evaluating the role of peripheral information in human movement is to use techniques designed to interrupt or disrupt afferent function. Unfortunately, procedures that attempt to interfere with the flow of kinesthetic information to the central nervous system via peripheral nerve blocks are rife with problems (Kelso, Stelmach, \& Wanamaker, 1974; Kelso, Wallace, Stelmach, \& Weitz, 1975). What is required is a preparation that selectively eliminates an important source of kinesthetic input without significantly impairing peripheral motor structures. Surgical operations on man (and woman!) that replace joints provide a potential means for deriving important inferences on the role of kinesthesis in movement perception and control. Common to

This research was supported by grants AM-25814 and NS 13617 from the National Institute of Health. A preliminary version of this paper, entitled "Finger Localization Following Total Joint Arthroplasty," was presented at the Psychonomic Society meetings in San Antonio, Texas, November 1978. We would like to thank Franklin S. Cooper and Michael T. Turvey for their helpful remarks on an earlier version. such procedures is that the joint capsule-which purportedly accommodates receptors for position and movement (Skoglund, 1956; Somjen, 1972)-is completely removed and the joint surfaces replaced. A unique opportunity thus arises for examining motor performance in the absence of the capsular component of peripheral receptor mechanisms. This is of particular significance, for recent theoretical papers and many critical reviews (Mountcastle, 1968; Roland, 1978) refer invariably to joint receptors as detectors of joint angle, and even as crucial to motor timing (Adams, 1977; but see also Kelso, 1978). Although Adams (1977) recognized the possibility that the "other senses," such as touch and muscle proprioception, may contribute to limb positioning, he nevertheless was adamant that "in an inconstant world, they must give way theoretically to joint receptors which always fire during movement and so are completely reliable sources of information" (p. 518). Neither the current physiological data on joint receptors nor the behavioral data that we shall present support such a proposition. In contrast, our findings indicate that the presence of joint receptors is not a necessary condition for detecting limb position. Moreover, joint receptors are extremely unlikely candidates for primary status in the temporal control of movement (see Keele, 1980, for possible alternatives). We take advantage of our findings to elaborate upon a different style of control-initially 
promoted by Soviet theorists (Bernstein, 1967; see also Greene, 1972; Turvey, 1977)-that fits our general perspective on the nature of coordinated movement (Kelso, Southard, \& Goodman, 1979a, 1979b).

The work of Skoglund (1956) and Boyd and Roberts (1953) is typically regarded as a demonstration that joint afferent discharge is angular specific. Single neurons from slowly adapting receptors in the capsule of the cat knee joint were shown to fire maximally at particular joint angles and with a sensitive range of 15 to $30 \mathrm{deg}$. Unfortunately, recent and extensive data fail to confirm the early findings that joint afferents discharge at intermediate angles, although they support the view that much more activity is seen at the very extremes of flexion and extension (Burgess \& Clark, 1969; Lynn, 1975). In fact, when the popliteus muscle, which is located posterior to the knee joint, is carefully removed, the midrange response is eliminated (Grigg \& Greenspan, 1977). Furthermore, the small number of midrange fibers found are strongly sensitive to succinylcholine chloride, a drug that is selectively responsive to muscle receptors. In contrast, no such sensitivity is observed in joint receptors that fire at the end of the movement range (Clark \& Burgess, 1975). Obviously, it would be useful to corroborate this new neurophysiological data with information from humans who have lost joint capsular afferents. In fact, some work has already been done in this regard. Grigg, Finerman, and Riley (1973), for example, performed a number of psychophysical tests on patients who had undergone total hip replacement. Their results revealed that loss of position sense was restricted, but only slightly so, to passive movements. Active movements showed no such deficit. It seems possible, however, that this result may be confounded by the fact that the hip joint is intrinsically involved in locomotory activities which, if animal evidence is a guide, do not require ongoing kinesthetic information (see Grillner, 1975, for a review). Thus, we might expect, for example, to see considerable differences in kinesthetic sensitivity between hip and finger joints. Indeed, a single comprehensive statement about the general properties of joint afferents across different joints has proved somewhat elusive. Although observations of knee and elbow joints on cats and primates are similar in failing to show midrange responses, evidence from costovertebral (Goodwin-Austin, 1969) and temporomandibular joints (Thilander, 1961) indicates the presence of full-range receptors.

In the present experiments, we examined the accuracy of movement reproduction of the index finger following complete surgical removal of the metacarpophalangeal (MP) joints in the hands of patients suffering from rheumatoid arthritis. In all cases, the inserted "prosthesis" was one developed by Swanson (1972) and made of silastic rubber. In essence, the device is not so much an articulated prosthesis as an implant designed to hold apart the two bone surfaces of the metacarpal and the proximal phalanx. In surgery, extensive dissection of soft tissues is needed, and any remaining ligamentous tissue that has not been destroyed by disease is detached and frequently excised to allow proper alignment and repositioning of the bones containing the implant. Some surgeons attempt ligamentous reconstruction, but it has been our practice not to do so because of the inadequacies of local tissues. None of the patients tested here had any ligamentous reconstruction done as part of the implant procedure. Hence, it is very unlikely indeed that the Golgi-tendon receptors of the ligaments played a role in signaling movement or position in these patients. Most patients had all four MP joints replaced, and all patients had the MP joint of either the right or left index finger excised and replaced by an implant. The illustration provided in Figure 1 shows that the metacarpal head has to be excised and a significant portion of the base of the metacarpal trimmed to allow the proper reception of the silastic rubber "prosthesis."

The movements allowed by the positioning device (see Figure 2 and below for details) were flexion and extension of the index finger about the MP joint. In an earlier study (discussed briefly in Kelso, 1977), patients $(n=5)$ and normal subjects $(n=12)$ performed -in the absence of vision-12 preselected and 12 constrained movements into each of three movement sectors defined initially by the experimenter. The basic experimental paradigm was one common to many studies in the area broadly known as short-term motor memory (e.g., see Laabs, 1973; Stelmach, 1974, for reviews). For preselected movements, instructions were to "select" a short, medium, or long movement of the finger and then, following a 2-sec interval, to "move" to the desired position. In this case, therefore, subjects were free to choose their desired movements with the only

A.

B.

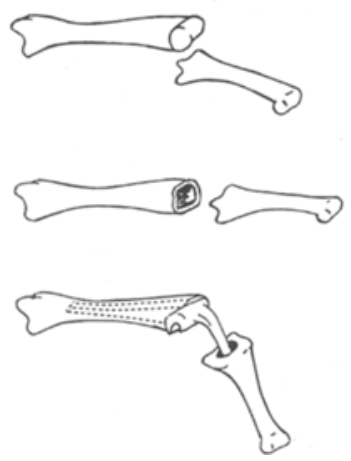

Figure 1. (A) The head of the metacarpal is resectioned and the adjacent bones are drilled longitudinally and trimmed appropriately to make way for the flexible silicone rubber implants. The largest implant that can be well seated is used. (B) The index finger illustrating the prosthesis in position. The implant is a dynamic spacer that acts as an internal mold to maintain proper joint alignment. (Adapted from Swanson. 1972.) 
restriction being that they disperse their selections within a given sector as much as possible. For constrained movements, the commands were "ready" followed by "move," and the patient moved until he/she located a mechanical stop defining the movement. Thus, subjects made constrained, exploratory movements, since no prior selection was possible. Patients in both conditions reproduced the criterion movement with the stop removed following their passive return to the starting position, which remained constant throughout.

A main feature of our data was that there were minimal differences between normal subjects and jointreplacement patients. On preselected movements, the mean absolute reproduction error of normal subjects was $2.98 \mathrm{deg}$ ( $1 \mathrm{deg}=2 \mathrm{~mm}$ measured at the tip of the index finger) compared to $3.13 \mathrm{deg}$ for the jointreplacement group. Although errors on constrained movements were slightly higher overall, the remarkable result was that the removal of joint-afferent information had no effect whatsoever (means $=4.44 \mathrm{deg}$ and $3.97 \mathrm{deg}$ for normals and joint-replacement patients, respectively). This finding was in sharp contrast to a situation in which normal subjects $(n=12)$ performed under conditions in which joint and cutaneous information was eliminated via the application of a child's sphygmomanometer (blood pressure cuff) at the wrist. This technique has the advantage of preserving muscle function in finger flexors and extensors, since these muscles lie high in the forearm above the cuff (Kelso, 1977; Merton, 1964). While preselected performance was hardly affected (mean = $3.35 \mathrm{deg}$ ), there were considerable deleterious effects under constrained, exploratory conditions (mean = $13.34 \mathrm{deg}$ ). Indeed, phenomenological reports revealed that wrist-cuff subjects could not perceive the locus of the mechanical stop when performing constrained movements. This was not the case for joint-replacement patients.

While these data are highly suggestive that jointafferent information is not crucial for the perception and control of movement, we must emphasize that patients in our initial experiment varied in the extent of the postoperative recovery period from 6 weeks in one case to over a year in another. An examination of the individual data, however, did not reveal any sizable systematic differences between patients as a function of the postoperative period. Nevertheless, we felt it important that fully fledged experiments be conducted on patients as soon after the operation as possible.

\section{EXPERIMENT 1}

\section{Method}

The follow-up experiments were on 13 patients who were examined during a period from 2 days to 4 weeks following total MP joint arthroplasty. The basic experimental procedure

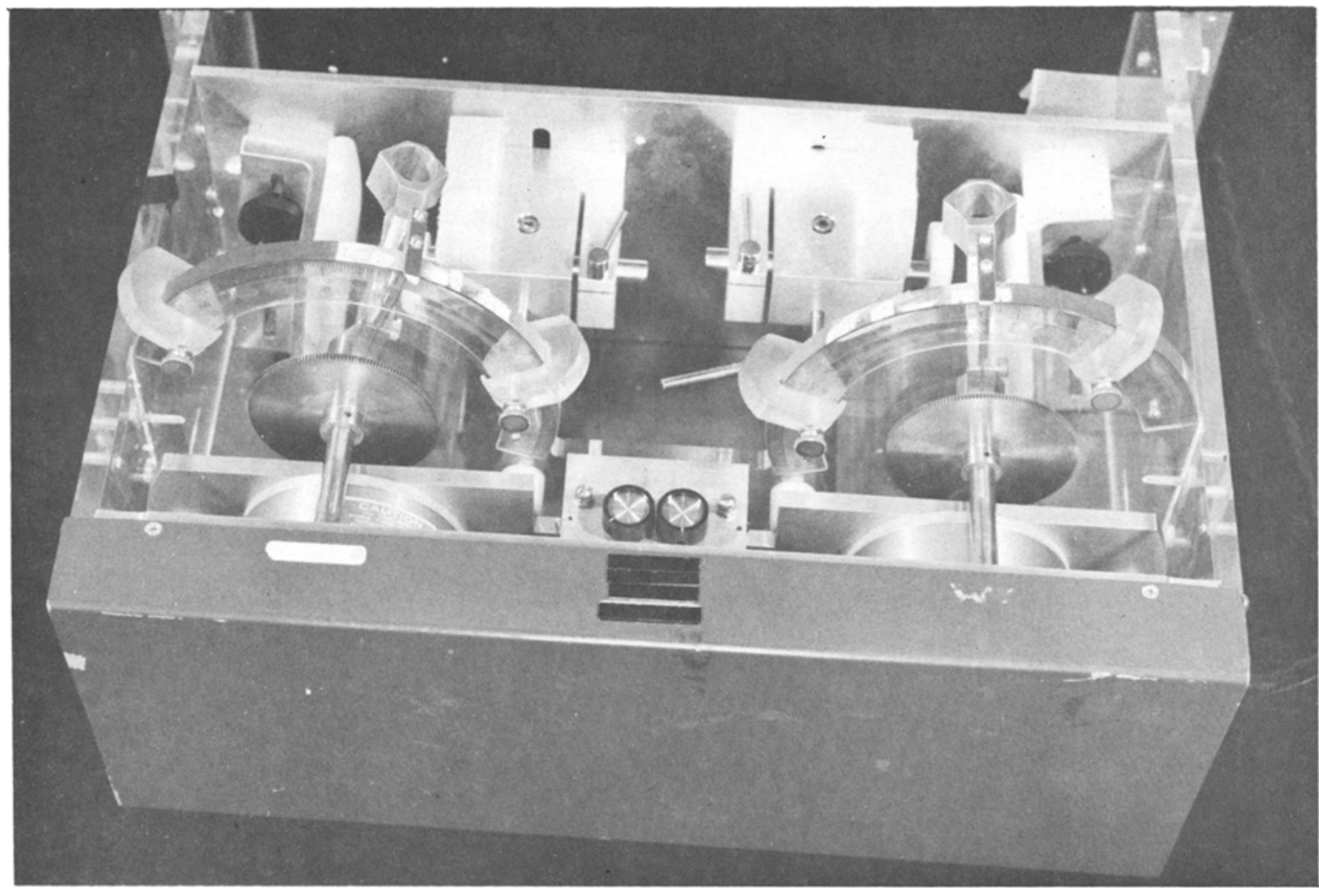

Figure 2. The finger positioning device. The apparatus allows for relatively friction-free movement about the metacarpophalangeal joint of the right or left index finger. 
in this study was, with one exception, identical to that employed in our preliminary work. Patients performed 12 preselected, 12 constrained, and 12 passive trials into one of three movement sectors. The movements involved flexion of the index finger at the MP joint alone. The distal end of the patient's finger was fitted with a plastic collar that slipped into an open-end cylindrical support (see Figure 2). The support revolved around the MP joint and prevented movement of the distal joints of the finger. Attached to the end of the support was a pointer, which moved over a protractor graduated in degrees. The device was also equipped with padded adjustable clamps with which to secure the patient's wrist, hand, and remaining fingers and thumb during the movement. Only the preferred hand was placed in the device, while the other rested on the patient's lap. Vision of the hand was obscured by an aluminum screen. The starting position of the finger on all trials was $20 \mathrm{deg}$ flexion and the maximum movement seldom exceeded $65 \mathrm{deg}$ flexion. Patients were instructed to distribute their selections as much as possible within a sector. Preselected movements always came first in the series and constrained movements were yoked to them in order to make an analysis of errors possible. In addition, a passive condition was included in which, following the verbal command "ready," the patient was moved passively to a stop and then returned to the starting position. Time at the endpoint of the movement was held constant at $2 \mathrm{sec}$. In all three movement conditions, patients reproduced actively $2 \mathrm{sec}$ following their return to the starting position. Although velocities were not measured, the movements in all cases were relatively slow with an approximate range of 20-30 deg per second. Absolute (unsigned), constant (signed), and variable errors (the standard deviation around the mean constant error) were collapsed across sectors and analyzed in a 3 (movement conditions) by 3 (movement sector) analysis of variance.

\section{Results and Discussion}

The main effect of movement conditions was significant for absolute and variable error only $[\mathrm{Fs}(2,24)=$ $12.30, p<.001$, and $3.39, p<.05$, respectively]. For absolute error, preselected movements were superior to passive and constrained, which were not different from each other (see Figure 3). A similar pattern of results obtained for variable error. In this case, preselected was superior to passive but not constrained conditions, although the latter two were not different from each other.

Neither the sectors main effect nor the interaction of sectors and conditions was significant for any of the dependent variables. The superiority of preselection over constrained and passive conditions shown in Figure 3 replicates much of our previous work and has been discussed in detail elsewhere (Kelso \& Stelmach, 1976; Roy \& Diewert, 1975). But the most interesting finding for the present discussion is the level of error in constrained and passive conditions. It is quite obvious that the patients in this study compare favorably with their counterparts in our preliminary experiment; more important, they performed within normal ranges. ${ }^{1}$ This is a fascinating finding, particularly in light of the classical role given by most physiologists and psychologists to joint receptors in the perception of movement and position (e.g., Adams, 1977; Roland, 1978). That is, "classical" conceptions of kinesthesis are built upon the angular specificity viewpoint-a notion contrary to very

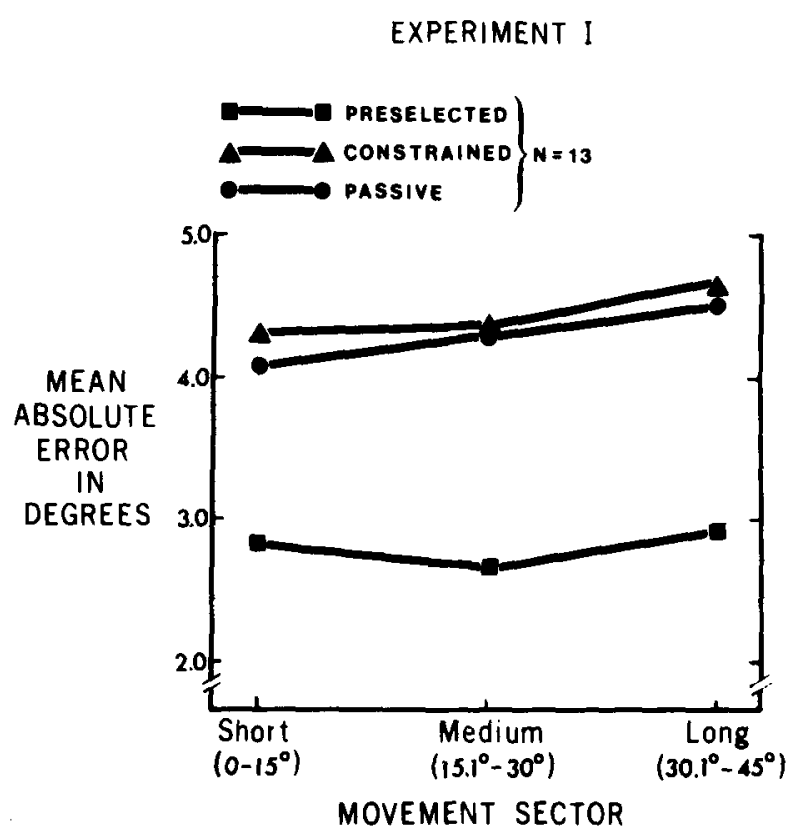

Figure 3. Mean absolute error in degrees for joint-replacement patients as a function of movement extent.

recent physiological work and obviously at variance with our data.

But what are the alternatives to joint receptors? Whether tactile information is sufficient to account for the performance of joint-replacement patients is open to question. ${ }^{2}$ Goldscheider's (1889) work, in which the skin was anesthetized via an AC electric current, revealed no disturbing effects on movement perception. More recently, however, the Swedish surgeon, Moberg (1972), in a rather unique patient, has shown that although joint-receptor information was unavailable, perception of passive motion and position was preserved with only skin receptors in function. Another alternative is that cutaneous inputs facilitate access to the central nervous system by muscle receptors. If this is the case, a strong argument could be generated for the role of muscle receptors in the conscious appreciation of movement-a stance that is receiving increasing support (cf. Kelso, 1978; Matthews, 1977, for reviews).

In previous experiments, we should note that patients had several sources of information available to them that may have assisted accurate movement production. Patients knew, for example, that the starting position of the finger remained the same throughout testing. Thus, they could use other information-such as duration or velocity-as a means for arriving at the correct final position. In Experiment 2, we examined this proposition by considering performance under conditions in which the starting position changed for the reproduction movement, thereby disrupting either the amplitude moved or the final end position reached. Under one condition, the patient was asked to produce the final position, while another condition required the patient to reproduce the same amplitude or distance. 


\section{EXPERIMENT 2}

\section{Method}

The same patients participated in this study as in Experiment 1. The apparatus was also the same as in the previous experiment. Criterion movements were presented from a starting position of $20 \mathrm{deg}$ flexion and were either 35,45 , or $50 \mathrm{deg}$ flexion, the latter being randomly defined. Patients without vision of their limbs moved actively to mechanical stops that specified these movements and then were returned to a starting position that was either $5 \mathrm{deg}\left(\mathrm{SP}_{1}\right)$ or $15 \mathrm{deg}\left(\mathrm{SP}_{2}\right)$ beyond the original starting position (i.e., in 15 or 5 deg flexion). They then reproduced either the final position or the amplitude of movement. Patients performed 12 trials on each condition; order was counterbalanced across subjects. There were therefore two trials on each criterion movement-starting position combination, which were collapsed for inspection of mean absolute and constant errors.

\section{Results and General Discussion}

For absolute and constant error, there was a significant interaction between movement conditions and starting position $[\mathrm{Fs}(1,12)=7.76, \mathrm{p}<.02$, and 11.27 , $p<.01$, respectively]. In Figure 4 , it is clear, and an analysis of simple effects reveals, that location is superior overall to amplitude and that the effect is magnified at the extreme starting position. The superior performance of location over amplitude is not unique to the joint. replacement population; this finding has also been obtained in studies of arm movements in normal subjects under both preselected (Stelmach, Kelso, \& Wallace, 1975) and constrained conditions (e.g., Keele \& Ells, 1972; Laabs, 1973). More interestingly, amplitude performance is biased in the direction of the final position presented. Thus, while location performance is hardly affected by changes in starting position, amplitude performance appears to reflect a bias to reproduce location. This finding suggests rather strongly that location is the important "code"; even though instructed to reproduce amplitude, the motor system appears to be optimally organized for achieving final position. The latter, we should emphasize, does not crucially depend upon slowly adapting joint receptors. Indeed, in earlier work on normal subjects, a very similar finding was obtained between amplitude and location when both joint and cutaneous inputs were removed (Kelso, 1977).

One way of interpreting these data is that there is a location code based on information provided by some type of peripheral receptor or set of receptors. Reproduction of location may then be viewed as a matching of receptor inputs to the stored referent or spatial code. Reproduction of distance, however, is much more difficult in that the change in starting position requires an additional subtractive process relative to the spatial code. Thus, to reproduce accurately, a new spatial code must somehow be derived to take into account the change in starting position (e.g., Stelmach \& McCracken, 1978).

An alternative explanation, and one that has gained status in recent papers (Bahill \& Stark, 1979; Bizzi,
EXPERIMENT II
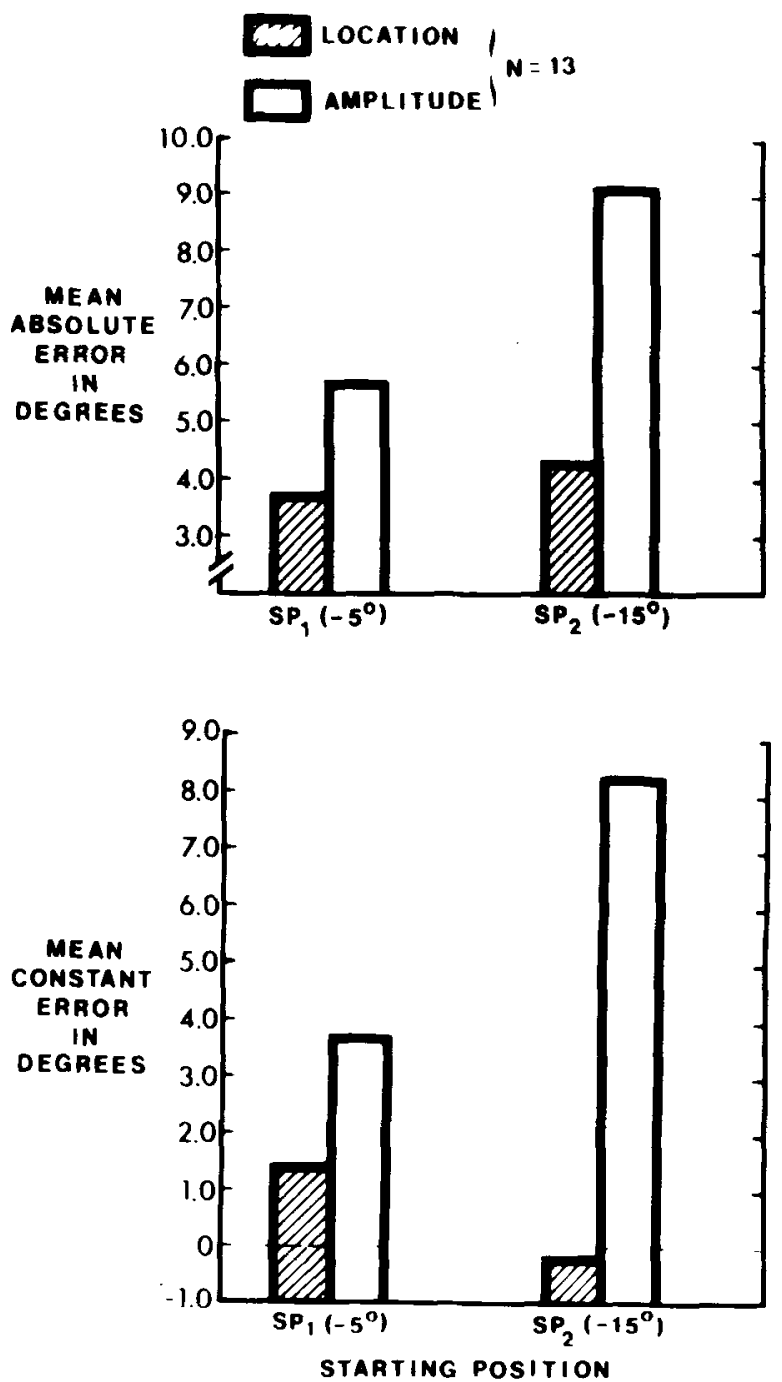

Figure 4. Mean absolute (unsigned) and constant (signed) error for joint-replacement patients as a function of changing starting position. Under one condition (location), the patient was asked to reproduce final position, while the other condition required the patient to reproduce the same amplitude or distance.

Dev, Morasso, \& Polit, 1978; Kelso, 1977; Kelso \& Holt, 1980), takes advantage of the natural physical properties, such as damping, stiffness, and inertial resistance, that are inherent in neuromuscular control systems. Typically, muscle-joint linkages are viewed as homeomorphic vibratory systems, the most specific example being a mass-spring (Asatryan \& Fel'dman, 1965; Fel'dman, 1966). Our findings may be interpreted as displaying an important characteristic of a mass-spring system, namely, that of equifinality (von Bertalanffy, 1973). That is, despite changes in initial conditions (displacement of a limb to a new starting position, mechanical perturbations), a massspring system will always reach an invariant final position or equilibrium point, determined only by the 
parameter specifications. For example, Polit and Bizzi (1978) in their recent work trained monkeys to point with an unseen arm to target lights. At random intervals and prior to pointing, a torque motor displaced the arm further away from, closer to, or even beyond the target. In spite of such alterations of kinesthetic input, the final position was always reached. These data suggest that final position is determined via the specification of stiffness and damping parameters that establish an equilibrium point between opposing pairs of muscles. That kinesthetic information is not crucial to this type of mechanism is revealed by identical results in animals who had undergone bilateral dorsal rhizotomy.

An argument can be made, therefore, that the neuromuscular organization underlying achievement of location has features qualitatively similar to a vibratory system. Note that the two viewpoints discussed here differ considerably in perspective. The former argues that the kinematic details of movements are represented in a spatial code. Thus, location as the endpoint of a movement may be described in reference to some internal coordinate system. While this may be a legitimate description, it refers to kinematics and not dynamics. The point should be clear when it is realized that it is the dynamics (e.g., force, viscosity, etc.) that determine the movement kinematics. From a dynamic perspective, then, terminal location is equated with the steady state of a system and is determined only by the parameters selected. Nowhere is there a need to represent kinematic details (Fitch \& Turvey, 1978)-it is in the nature of a vibratory system to achieve equilibrium. While the present experiments cannot entirely differentiate these alternatives, the parsimony of the dynamic description is appealing. The vibratory system viewpoint clearly negates reliable reproduction of distance (a kinematic detail) from variable initial conditions. Furthermore, that accurate achievement of final position can obtain in the absence of slowly adapting joint afferents muddies the common view that angular-specific receptors contribute to the development of a spatial code.

Finally, it behooves us to consider briefly the theoretical role that joint receptors may play in the control of movement, particularly in light of recent debates on the topic (e.g., Adams, 1977; Kelso, 1978). One possibility arises out of Grigg's (1976) work showing that a sizable proportion of afferents in cat medial articular nerve fire as a function of the degree of torque developed at a fixed joint position. This finding suggests that muscular contractions activate joint neurons and that joint afferents can function as load detectors. But another, more intriguing, notion with potentially broad theoretical consequences may be found in a diversion from traditional views of peripheral mechanoreceptors. Such receptors have typically been regarded as contributing-or not contributing-specific types of kinematic information (e.g., position, rate, acceleration) to higher brain centers for use in control and termina- tion of movements. Suppose, however, that peripheral receptor information is not dimension-specific; rather, it merely serves to bias interneuronal pools in the spinal cord so as to lower the threshold at which signals may be generated to the musculature. Thus, the function of mechanoreceptors is simply to "tune" the interneuronal pool so that central command pulses may have an optimal facilitatory effect on the muscles served by that pool. The research of Aizerman and his colleagues (Aizerman \& Andreeva, 1968; Chernov, 1968) has provided evidence for this viewpoint with reference to muscle spindle function in such activities as postural adjustment, pain avoidance, and precision aiming. For example, if a person in a relaxed standing position is pushed in the back, the spindles in the gastrocnemius and hamstring muscle groups will be stretched. An undifferentiated supraspinal command pulse results in the activation of only those muscles whose spindle inputs define the background state of the interneuronal pool. Consequently, selective activation of the stretched muscles automatically gives rise to forces that preserve vertical posture. It seems eminently possible that the control system may also use cutaneous and joint inputs to serve similar "tuning" functions. In fact, when we realize that human stretch reflex function is virtually eliminated when joint and cutaneous information is removed (Marsden, Merton, \& Morton, 1972), this hypothesis gains respectability. One obvious beauty of such a system is that the brain does not have to select which muscles to contract; rather, muscles are activated by virtue of the dynamic state of the interneuronal pools. Moreover, if all proprioceptive inputs serve a tuning function, it makes little sense to assign priority to any single source such as joint receptors. The latter proposal is obviously incompatible with the well-known redundancy ${ }^{3}$ of structures in sensorimotor systems (cf. Cohen, 1964), while the notion of information-astuning is obviously not. Multiplicity (and reciprocity) of function protect against the loss of particular components and corresponding behavioral deficits. Thus, the removal of any one afferent source or even all of them will not necessarily debilitate a collective of muscles; it may, however, as Fel'dman (1974) points out, reduce the stability of limb transition processes and the speed with which they are produced. Fel'dman's analysis points to the importance of looking closely at limb trajectories in studies that manipulate proprioception-a step that few studies have taken thus far and that the present data cannot address.

Our findings do indicate that joint-replacement subjects are extremely accurate in attaining final limb positions, a result that is not particularly surprising when considered within the dynamic view of motor organization that we have briefly elaborated. The present data are detrimental, however, for a view that assumes that regulation of movement is largely effected by the receptor firing functions of joint afferents. 


\section{REFERENCES}

Adams, J. A. Feedback theory of how joint receptors regulate the timing and positioning of a limb. Psychological Review, 1977, 84, 504.523.

Adams, J. A. Theoretical issues for knowledge of results. In G. E. Stelmach (Ed.), Information processing in motor control and learning. New York: Academic Press, 1978.

Aizerman, H. A., \& Andreeva, E. A. Simple search mechanism for control of skeletal muscle. Automation and Remote Control, 1968, 29, 452-463.

Asatryan, D. C., \& Fel'dman, A. D. Functional tuning of the nervous system with control of movement or maintenance of a steady posture. I. Mechanographic analysis of the work on the joint on execution of a postural task. Biophysics, 1965, 10, 925-935.

Bahill, A. T., \& Stakk, L. The trajectories of saccadic eye movements. Scientific American, 1979, 41, 542-555.

Bernstein, $\mathbf{N}$. The coordination and regulation of movement. New York: Pergamon Press, 1967

Bizzi, E., Dev, P., Morasso, P., \& Polit, A. Effects of load disturbance during centrally initiated movements. Journal of Neurophysiology, 1978, 41, 542-556.

Boyd, I. A., \& Roberts, T. D. M. Proprioceptive discharges from stretch receptors in the knee-joint of the cat. Journal of Physiology, 1953, 122, 38-58

Burgess, P. R., \& Clark, F. S. Dorsal column projection of fibers from the cat knee joint. Journal of Physiology, 1969, 203, 301-315.

Chernov, V. I. Control over single muscles of a pair of muscleantagonists under conditions of precision search. Automation and Remote Control, 1968, 29, 1090-1101.

Clark, F. J., \& Burgess, P. R. Slowly adapting receptors in cat knee joint: Can they signal joint angle? Journal of Neurophysiology, 1975, 38, 1448-1463.

CoHEN, M. J. The peripheral organization of sensory systems. In R. F. Reiss (Ed.), Neural theory of modelling. Stanford, Calif: Stanford University Press, 1964.

Edelman, G. M. Group selection and phasic reentrant signalling: A theory of higher brain function. In G. M. Edelman \& V. B. Mountcastle (Eds.), The mindful brain. Cambridge, Mass: M.I.T. Press, 1979.

Fel'dman, A. G. Functional tuning of the nervous system with control of movement or maintenance of a steady posture. III. Controllable parameters of the muscles. Biophysics, 1966, 4, 565-578.

Fel'dman, A. G. Control of the length of muscle. Biophysics, $1974,19,766-771$.

Fitch, H. L., \& Turvey, M. T. On the control of activity: Some remarks from an ecological point of view. In D. M. Landers \& R. W. Christina (Eds.), Psychology of motor behavior and sport. Champaign, Ill: Human Kinetics, 1978.

Goodwin-Austin, R. B. The mechanoreceptors of the costovertebral joints. Journal of Physiology, 1969, 202, 737-753.

Goldsche IDE R, A. Untersuchungen über den Muskelsinn. Archiv für Anatomie und Physiologie (Leipzig), 1889, 3, 369-502.

Greene, P. H. Problems of organization of motor systems. In R. Rosen \& F. Snell (Eds.), Progress in theoretical biology (Vol. 2). New York: Academic Press, 1972.

GrigG, P. Response of joint afferent neurons in cat medial articular nerve to active and passive movements of the knee. Brain Research, 1976, 118, 482-485.

Grigg, P., Finerman, G. A., \& Riley, L. H. Joint position sense after total hip replacement. Journal of Bone and Joint Surgery, 1973, 55, 1016-1025.

Grigg, P., \& Greenspan, B. J. Response of primate joint afferent neurons to mechanical stimulation of knee joint. Journal of Neurophysiology, 1977, 40, 1-8.

GrillNER, S. Locomotion in vertebrates: Central mechanisms and reflex interaction. Physiological Reviews, 1975, 55, 247-304
KEELE, S. W. A behavioral analysis of motor control. In V. Brooks (Ed.), Handbook of physiology: Motor control. Washington, D.C: American Physiological Society, 1980.

KEELE, S. W., \& ElLS, J. G. Memory characteristics of kinesthetic information. Journal of Motor Behavior, 1972, 4, 127-134.

KeLso, J. A. S. Motor control mechanisms underlying human movement reproduction. Journal of Experimental Psychology: Human Perception and Performance, 1977, 3, 529-543.

Kelso, J. A. S. Joint receptors do not provide a satisfactory basis for motor timing and positioning. Psychological Review, $1978,85,474-481$.

KELSO, J. A. S., \& HolT, K. G. Exploring a vibratory systems analysis of human movement production. Journal of Neurophysiology, 1980, 43, 1183-1196.

Kelso, J. A. S., Southard, D. L., \& Goodman, D. On the coordination of two-handed movements. Journal of Experimental Psychology: Human Perception and Performance, 1979, 5, 229-238. (a)

Kelso, J. A. S., Southard, D., \& Goodman, D. On the nature of human interlimb coordination. Science, 1979, 203, 1029-1031. (b)

Kelso, J. A. S., \& Stelmach, G. E. Central and peripheral mechanisms in motor control. In G. E. Stelmach (Ed.), Motor control: Issues and trends. New York: Academic Press, 1976.

Kelso, J. A. S., Stelmach, G. E., \& Wanamaker, W. M. Behavioral and neurological parameters of the nerve compression block. Journal of Motor Behavior, 1974, 6, 179-190.

Kelso, J. A. S., Wallace, S. A., Stelmach, G. E., \& Weitz, G. A. Sensory and motor impairment in the nerve compression block. Quarterly Journal of Experimental Psychology, 1975, 27, 141-147.

LAABS, G. J. Retention characteristics of different cues in motor short-term memory. Journal of Experimental Psychology, 1973, 100, 168-177.

LyNN, B. Somatosensory receptors and their CNS connections. Annual Reviews of Physiology, 1975, 37, 105-127.

Marsden, C, D., Merton, P. A., \& Morton, H. B. Servo action in human voluntary movement. Nature (London), 1972. 238, 140-143.

Matthews, P. B. C. Muscle afferents and kinesthesia. British Medical Bulletin, 1977, 33, 137-142.

Merton, P. A. Human position sense and sense of effort. Homeostasis and feedback mechanisms. In 18th Symposium of the Society of Experimental Biology. Cambridge, England: Cambridge University Press, 1964.

Moberg, E. Fingers were made before forks. The Hand, 1972, 4, 201-206.

Mountcastle, V. B. Medical physiology (Vol. 2; 12th ed.). St. Louis, Mo: Mosby, 1968.

NEwELL, K. M. Knowledge of results and motor learning. In J. Keogh (Ed.), Exercise and sports sciences reviews. Santa Barbara, Calif: Journal Publishing Affiliates, 1977.

Polit, A., \& Bizzi, E. Processes controlling arm movements in monkeys. Science, 1978, 201, 1235-1237.

Roland, P. E. Sensory feedback to cerebral cortex during voluntary movements in man. Behavioral and Brain Sciences, 1978 , $1,129-147$

Roy, E. A., \& Diewert, G. L. Encoding of kinesthetic extent information. Perception \& Psychophysics, 1975, 17, 559-564.

Skoglund, S. Anatomical and physiological studies of knee joint innervation in the cat. Acta Physiologica Scandinavica Monograph Supplement, 1956, 124, 1-99.

SomJEN, G. Sensory coding in the mammalian nervous system. New York: Appleton-Century-Crofts, 1972.

Stelmach, G. E. Retention of motor skills. Exercise and sports sciences reviews (Vol. 2). New York: Academic Press, 1974.

Stelmach, G. E., Kelso, J. A. S., \& Wallace, S. A. Preselection in short-term motor memory. Journal of Experimental Psychology: Human Perception and Performance, 1975, 1, 744-755. 
Stelmach, G. E., \& McCracken, H. D. Storage codes for movement informatiớ. In J. Requin (Ed.), Attention and performance VII, Hillsdale, N.J: Erlbaum, 1978.

SwANSON, A. B. Flexible implant arthroplasty for arthritic finger joints. The Journal of Bone and Joint Surgery, 1972, 54A, 435-455.

Thilander, B. Innervation of the temporomandibular joint capsule in man. Transactions of the Royal School of Dentistry, Stockholm, 1961, 7, 9-67.

Turvey, M. T. Preliminaries to a theory of action with reference to vision. In R. Shaw \& J. Bransford (Eds.), Perceiving, acting and knowing. Hillsdale, N.J: Erlbaum, 1977.

von Bertalanffy, L. General system theory. London: Penguin Books, 1973.

\section{NOTES}

1. We do not feel it necessary to obtain further data on normal subjects for purposes of comparison here. In addition to our earlier work discussed in the introduction, we have performed other studies on normal individuals using exactly the same apparatus as employed in the present experiments. In one experiment (Kelso \& Holt, 1980), subjects made 30 positioning movements and, after each movement, were provided with knowledge of results regarding their accuracy (which was not the case in the present work). Even with these procedures designed to improve performance (and recognized as doing so; see Adams, 1978, and Newell, 1977, for reviews), the mean absolute and variable errors were $2.81 \mathrm{deg}$ and $3.14 \mathrm{deg}$, respectively. If anything, the "normalcy" of the present jointreplacement data is strengthened by these results.

2. It seems obvious that a simple experiment in which the skin was anesthetized would provide an answer to the question of a tactile role. We did not do this because the ethics of using invasive techniques on these people, who have extensive rheumatoid arthritis, are highly questionable-to most human subjects committees, as well as to us.

3. A more appropriate term than redundancy may be degeneracy (Edelman, 1979). One of the problems with the term redundancy is that it characterizes identical structures; yet, the morphological characteristics of joint, cutaneous, and muscle receptors are quite different. In contrast, Edelman's term degeneracy implies the presence of multiple receptor types with different structures, but capable of carrying out the same function (Edelman, 1979, p. 58).

(Received for publication September 7, 1979; revision accepted February 29, 1980.) 